\title{
El arbitraje en derecho público ecuatoriano
}

\author{
Antonio José Pérez* \\ Recibido/Received: 27/06/2019 \\ Aceptado/Accepted: 27/08/2019
}

\begin{abstract}
Sumario:1.Antecedentedelderechopúblicolatinoamericano y la relevancia del principio de legalidad. 2. Distinción entre los contratos civiles y contratos públicos en el contexto arbitral. 3. Normas aplicables al arbitraje en derecho público. 4. Arbitrabilidad y transigibilidad. 5. El arbitraje en los distintos contratos estatales del Ecuador. 5.1 Tratados Bilaterales de Inversión. 5.2 Contratación Pública. 5.3 Contratos de Inversión. 5.4 Contratos de Concesión. 5.5 Alianzas Público-Privadas.
\end{abstract}

Resumen: El Ecuador no logra un consenso respecto a las reglas del arbitraje en materia de derecho público, que es el único que rige en la administración pública y sus contratos. Las profundas diferencias frente al derecho privado que no son comprendidas adecuadamente ocasionan sesgos y desconfianza. Es urgente regular apropiadamente el arbitraje con el sector público, específicamente alineando los parámetros de la Ley de Arbitraje y Mediación con la Constitución de la República de 2008, el Código Orgánico Administrativo, y las normas que han venido regulando la materia. Esto, para confirmar que el arbitraje es una alternativa idónea para fomentar la inversión. Recordemos, además, que un importante porcentaje de inversión en el país está ligado a los proyectos del Estado.

* Abogado especialista en derecho público y arbitraje en Bustamante \& Bustamante. Autor de
varias obras jurídicas. Correo electrónico: ajperez@bustamante.com.ec

A. J. PÉREz, "El arbitraje en derecho público ecuatoriano", Revista Ecuatoriana de Arbitraje, No. 10, 2019, pp. 269-288. 
Palabras Clave: contrato público, principio de legalidad, actos administrativos, arbitrabilidad.

\section{Arbitration in public ecuadorean law}

Aвstract: Ecuador has not reached a consensus regarding the rules of arbitration in matters of public law, which is the only one that governs public administration and its contracts. Deep differences with private law that are not properly understood cause biases and mistrust. It is urgent to properly regulate arbitration with the public sector, specifically aligning the parameters of the Arbitration and Mediation Law with the Constitution of 2008, the Organic Administrative Code and the rules that have been regulating the matter, in order to confirm that arbitration is an ideal alternative to promote investment. We must consider that a considerable amount of investment in the country, are linked to Government's projects.

KeYWORDs: public contract, principle of legality, administrative acts, arbitrability.

\section{Antecedente del Derecho Público Latinoamericano Y LA RELEVANCIA DEL PRINCIPIO DE LEGALIDAD}

El derecho público en la región latinoamericana proviene del denominado Derecho Continental Europeo, que incluye particularmente el derecho público (derecho administrativo ${ }^{1}$ ). Es imperativo comprender su contexto y su antecedente histórico para asimilar su rigidez y particular lógica, con cuyos elementos debe explorarse y aclararse, las salidas que propicien el arbitraje en el derecho público, respetando sus principios.

El derecho administrativo inicia referencialmente por los años 1799 con la Revolución Francesa, donde se configura el

1. El derecho público es el género y el derecho administrativo la especie. 
renacimiento de la estructura de poder, con la que se inicia el fin de las sociedades monárquicas y paulatinamente aparecen los primeros cimientos de los Estados modernos. Este cambio sustancial se da por la violenta reacción social contra la tiranía, la arbitrariedad y el abuso del poder de los reyes de la época.

Bajo teorías alimentadas por filósofos de la ilustración, la meta de la Revolución era conceptualmente trasladar la soberanía y el poder de la monarquía, hacia el pueblo. Este último, representado por la norma jurídica como la auténtica representante ${ }^{2}$. Después de siglos de evolución, el Código $\mathrm{Civil}^{3}$ alinea este hecho histórico con la definición respecto a la "Ley": una declaración de la voluntad soberana.

Pues bien, nuestro derecho público proviene de este antecedente histórico francés, influenciado en todo Europa y recogido en nuestro sistema jurídico. En consecuencia, nuestro derecho administrativo, tiene el reflejo del prejuicio contra la arbitrariedad del poder; ante lo cual, procuró crear un cerco normativo a las actuaciones de las autoridades públicas.

La rigidez de nuestro derecho en la región y en Europa, ha ocasionado ciertas trabas en la edad moderna; y como mejor lo explica el argentino Guido TAWIL ${ }^{4}$ los procesos de liberación del comercio, la globalización e integración económica han dado lugar a nuevos fenómenos, los mismos que reflejan un problema en la visión localista del derecho administrativo, específicamente, en el propio sistema francés que ha evitado alinearse al derecho comparado, salvo pocos ajustes con el derecho escandinavo, derecho alemán y norteamericano. El jurista argentino, continúa su reflexión apuntando en la necesidad de replantear un derecho administrativo supranacional, por el contexto global.

2. Se inicia con la "Declaración de los Derechos del Hombre y del Ciudadano" aprobada por la Asamblea Nacional Constituyente francesa, el 26 de agosto de 1789.

3. Código Civil, Art. 1, RO Sup. No. 46, 24/06/2005.

4. G. S. TAwIL, Estudios de Derecho Administrativo, AbeledoPerrot S.A., 2015, p. 657. 
Volviendo a la tradición del derecho administrativo, lo que ha dado lugar hoy en día a su extrema rigidez, es el principio de legalidad el mismo que afecta la actuación administrativa; $\mathrm{y}$, en consecuencia, a los contratos administrativos, lo que veremos a continuación.

\section{DistinCiÓN ENTRE lOS CONTRATOS CIVILES Y CONTRATOS PÚBLICOS EN EL CONTEXTO ARBITRAL}

El Código Orgánico Administrativo (en adelante, COA), que entró en vigor en julio de 2018, es aplicable de manera general a todos los contratos administrativos (o públicos) y los define como "[...] el acuerdo de voluntades productor de efectos jurídicos, entre dos o más sujetos de derecho, de los cuales uno ejerce una función administrativa" ${ }^{\prime 5}$.

El principio de legalidad, que caracteriza esta rama, explica que los funcionarios públicos sólo podrán ejercer “[...] las competencias y facultades que les sean atribuidas en la Constitución y la ley [...]"6. Este principio constitucional, no es más que una forma de traducir el clásico adagio que dice: "En derecho público sólo se puede hacer lo que está permitido", y que inversamente en derecho privado dice que "se puede hacer todo lo que no está prohibido".

El principio legalidad en contratos públicos considera distinciones fundamentales desde la formación previa del contrato en el denominado "proceso precontractual", que comprende desde la convocatoria hasta la suscripción del contrato, pero también la norma prevé aspectos en la ejecución contractual e incluso en el control ex post. En cada una de estas etapas, están disposiciones expresas y que no pueden ser sujetas a la libertad de las partes, aplicables independientemente de lo señalado en el contrato. Se trata de una mecánica compleja y

5. Código Orgánico Administrativo, Art. 125, RO Sup. No. 31, 07/07/2017.

6. Constitución de la República del Ecuador, Art. 226, RO No. 449, 20/10/2008. 
estricta, que es incompatible con la romántica idea de libertad y autonomía de la voluntad en el campo civil.

Por lo anotado, el contrato público estará más expuesto a la amenaza del fantasma de la nulidad, si no cumple con las disposiciones legales, independientemente de las nobles intenciones de las dos partes. Ya lo dice el propio Código Civil, "que habrá objeto ilícito en todo lo que contraviene al derecho público ecuatoriano"7 (énfasis añadido).

El irrespeto al principio de legalidad, afecta aspectos ulteriores de la actividad administrativa, como lo es la obligatoriedad de "motivación" de los actos administrativos". De ahí la importancia, no sólo para la parte pública sino para la parte privada, el procurar cumplir con las solemnidades, con independencia a la literalidad del contrato.

En los contratos civiles, las partes pueden imponer sus propias reglas en las cláusulas arbitrales -como en el resto de los compromisos-. Ya en el caso de un eventual conflicto entre privados, el papel de un Tribunal Arbitral (o judicial civil) será analizar el espíritu del acuerdo y la voluntad de las partes ${ }^{9}$ Pero cuando una de las partes es un ente público dentro de una controversia, tanto árbitros como jueces (del Contencioso Administrativo), deberán analizar a más del espíritu del acuerdo, las disposiciones legales que regían el contrato, que lo confirma la regla civil que señala que a "[...] todo contrato se entenderán incorporadas las leyes vigentes al tiempo de su celebración $[\ldots]^{10 \prime \prime}$.

Las cláusulas exorbitantes, por ejemplo, son aquellas incorporadas por mandato legal y que raramente están

7. Código Civil, N. 3, Art. 1478.

8. Constitución de la República, N. 6, Art. 76(7)(1).

9. Código Civil, N. 3, Art. 1561: "Todo contrato legalmente celebrado es una ley para los contratantes".

10. Ídem, Art. 7(18). 
contempladas en los contratos civiles. La igualdad se ve aparentemente, transgredida por ellas, pero en materia de derecho público los contratistas privados acceden a esas condiciones contractuales y no cabe alegar su desconocimiento o falta de igualdad, pues la ley se entiende conocida por todos ${ }^{11}$.

En este sentido, como lo dice Efraín PÉREZ ${ }^{12}$, un árbitro nacional o internacional, no podría juzgar el ejercicio de las cláusulas exorbitantes, desde la óptica privada o desde una legislación extraña. Pero lo que sí podría un Tribunal Arbitral, es determinar -como lo hacen los jueces del contencioso administrativo- si la actuación administrativa dentro del contrato no se extralimitó de sus facultades y fueron ajustadas a los requisitos materiales y formales, sin perjuicio del respeto de otros principios supra legales.

\section{Normas aplicables al Arbitraje en Derecho Público}

El enfrentamiento entre el principio de legalidad y la autonomía de la voluntad debe abordarse en el contexto de las normas que rigen la administración pública, en tres etapas aplicadas al proceso arbitral: (i) Convenio arbitral, (ii) Normas adjetivas, (iii) Normas sustantivas.

\subsection{Convenio arbitral}

Para acudir a arbitraje en sector público, a más de la "voluntad"13 de las partes, como se dijo, deben analizarse íntegramente las disposiciones legales y constitucionales que delimitan su campo. En este caso, se exige el arbitraje en derecho ${ }^{14}$ (a excepción de controversias derivadas de contratos de "deuda

11. Ídem, Art. 6.

12. E. Pérez, La arbitrabilidad del Acto Administrativo, Estructura y Administración del Estado $<$ http://estade.org/> (25/06/2019).

13. Ley de Arbitraje y Mediación, Art. 6, RO No. 417, 14/12/2006.

14. Código Orgánico Administrativo, N. 5, Art. 126. 
externa"15) y que requerirán en el caso de "contratación pública", el informe favorable del Procurador General del Estado. Esto último fue ampliado posteriormente, a los demás contratos estatales, según se interpreta de la Disposición General Quinta del Código Orgánico de Planificación y Finanzas Públicas que dice que previa autorización del Procurador General del Estado se podrá validar otra jurisdicción y legislación para la solución de divergencias o controversias en contratos celebrados por el Estado ${ }^{16}$. En principio, el Informe previo que el Procurador emite sobre la cláusula arbitral, tiene como fin analizar patologías o errores.

Podría ilustrarse un escenario hipotético en el que una autoridad pública, dentro de un contrato público suscrito con un privado estipule "arbitraje en equidad" -contrario a lo que dice nuestra norma ecuatoriana-. En materia civil, sería perfectamente factible, pero en derecho público no. Esta cláusula estaría viciada con nulidad y difícilmente podrá surtir efectos jurídicos, incluso contra terceros de buena fe.

Entre el universo de aspectos discutibles sobre este punto, también están corrientes internacionales como la figura de la "extensión del convenio arbitral a terceros no signatarios". En derecho civil, ha tenido sus reservas y algunos países han tolerado este escenario bajo ciertas circunstancias y requisitos. Pero su viabilidad ha estado prevista a lo dispuesto en las normas domésticas. Es el caso de la legislación peruana, en el art. 14 del Decreto Legislativo No. 1071 que en relación al arbitraje contempla:

Convenio arbitral se extiende a aquellos cuyo consentimiento de someterse a arbitraje, según la buena fe, se determina por su participación activa y de manera determinante en la negociación, celebración, ejecución o terminación del contrato que comprende el convenio arbitral o al que el convenio esté

15. Corte Constitucional del Ecuador, Sentencia Interpretativa No. 0001-09-SIC-CC.

16. Código Orgánico de Planificación y Finanzas Públicas, Disposición General Quinta, RO Sup. No. 306, 22/10/2010. 
relacionado. Se extiende también a quienes pretendan derivar derechos o beneficios del contrato, según sus términos ${ }^{17}$.

A diferencia de lo que explica la norma peruana, en el Ecuador nuestra Ley de Arbitraje y Mediación (en adelante, LAM) no es ambigua y señala claramente que "[e]l convenio arbitral es el acuerdo escrito en virtud del cual las partes deciden someter a arbitraje $[\ldots]^{18 \prime \prime}$. En derecho público, sería aún más difícil aventurarse por una línea interpretativa, sino lo prevé el ordenamiento expresamente.

\subsection{Normas Adjetivas}

La LAM -que entró en vigencia en el año 2006- dice que le serán supletorias las siguientes normas principalmente: el Código Civil, el ahora Código Orgánico General de Procesos (en adelante, COGEP) o el Código de Comercio ${ }^{19}$. Sin embargo, no debe perderse de vista que lo dispuesto por la Constitución tendrá prevalencia sobre todas las demás normas. Sin perjuicio de lo anotado, es necesario también el análisis integral del ordenamiento, especialmente sobre las normas dictadas posteriormente a la LAM.

Ya en las normas procesales, el COGEP, complementa la ritualidad subsidiaria del proceso arbitral. En materia de contratos públicos o administrativos, el artículo 300 nos dice que la jurisdicción contencioso administrativo tendrá "[...] por objeto tutelar los derechos y ejercer el control de legalidad de los hechos, actos administrativos o contratos del sector público [... $]^{20 \prime \prime}$.

Existen normas adjetivas claras y expresas en esta materia que dan parámetros para el arbitraje que involucra al sector

17. Dirección de Arbitraje Administrativo del OSCE - Perú, Decreto Legislativo No. 1071: Decreto Legislativo que norma el arbitraje, 01/09/2008, <https://bit.ly/2Lf6Q2g>.

18. Ley de Arbitraje y Mediación, N. 13, Art. 5.

19. Ídem, Art. 37.

20. Código Orgánico General de Procesos, Art. 300, RO Sup. No. 506, 22/05/2015. 
público, comenzando por las directrices que manda la propia Constitución, el COGEP (en la sección sobre el Contencioso Administrativo) y por supuesto, la misma LAM.

Adicionalmente, algunas cláusulas arbitrales, también prescriben como guía para la práctica de la prueba en los procesos, los lineamientos establecidos en las Reglas sobre la Práctica de Prueba en el Arbitraje Internacional de la International Bar Association (IBA) ${ }^{21}$, lo cual no existe inconveniente sobre su aplicación, en tanto y en cuanto no se contraponga con otras del ordenamiento jurídico aplicables.

Aeste punto, podría resultar algo decepcionante en materia de arbitraje, restringir normas procesales a las normas locales, sin embargo, es necesario ser prolijo dada la rigurosidad en materia de derecho público, que potencialmente es más susceptible a la declaratoria de nulidad, por las razones anotadas.

\subsection{Normas sustantivas}

Los jueces y los árbitros tienen las mismas competencias a la hora de juzgar y así lo ilustra Patricio AYLWIN cuando señala que "[l] os árbitros son jueces porque tienen jurisdicción, esto es facultad de administrar justicia. Son personas escogidas para juzgar un litigio"22. En normas sustantivas, el Código Orgánico de la Función Judicial (en adelantee, COFJ) da las pautas para la administración de justicia ${ }^{23}$. En igual sentido la tercera disposición de la LAM en cuanto al arbitraje en derecho dice que los árbitros deberán atenerse a la ley, a los principios universales del derecho, a la jurisprudencia y a la doctrina ${ }^{24}$.

21. Reglas de la International Bar Association sobre la Práctica de Prueba en el Arbitraje Internacional, <https://bit.ly/30LNEjb>.

22. P. Aylwin Azócar, El Juicio Arbitral, 5ta Ed., Editorial Jurídica de Chile, 2005, p. 150.

23. Código Orgánico de la Función Judicial, Art. 28, RO Sup. No. 544, 09/03/2009.

24. Ley de Arbitraje y Mediación, N. 13, Art. 3. 
El COFJ, en cuanto al papel de los jueces -también aplicable a los árbitros- dice que estos se limitarán a juzgar y hacer que se ejecute lo juzgado, con arreglo a la Constitución, los instrumentos internacionales de derechos humanos y las leyes de la República. Adiciona como principios y fuentes del derecho a la jurisprudencia, como herramienta para interpretar, integrar y delimitar el campo de aplicación del ordenamiento legal y -al igual que la LAM- incluye a la "doctrina", con la función de suplir la ausencia o insuficiencia de las disposiciones que regulan una materia ${ }^{25}$.

Esta inclusión es inusual en el resto de los países latinoamericanos, pues tradicionalmente se ha mantenido a la doctrina, como una herramienta no vinculante limitado para el entendimiento del derecho. Este detalle, aparentemente irrelevante, es sustancial a la hora de administrar justicia (jueces o árbitros), pues legitima a la doctrina como una suerte de fuente supletoria. El problema de ello es que el término "doctrina" es ambiguo y general definido como "el conjunto de ideas $u$ opiniones religiosas filosóficas, políticas, etc., sustentadas por una persona o grupo" ${ }^{26}$. Pero el potencial riesgo deviene que la doctrina es que no puede ser diferenciada entre la "autorizada" de la "no autorizada" y puede contener criterios erróneos, desactualizados, imprecisos o que reflejen simplemente otras realidades basados en otros contextos. En todo caso, la propia Ley la admite y esto incluye el arbitraje en derecho público, pero limitada ante la ausencia o insuficiencia de normas.

Bajo la premisa anterior, podría incluso reconocerse corrientes como la lex mercatoria, ante oscuridad o ausencia de la norma e incluso. Este escenario lo reconoce Rafael OYARTE ${ }^{27}$ y se refiere a ellas como "lagunas", de las que opina son originadas en los "[...] casos no previstos en el ordenamiento

25. Código Orgánico de la Función Judicial, N. 23, Art. 28.

26. Real Academia Española, Diccionario.

27. R. Oyarte, Debido Proceso, 2da Ed., Corporación de Estudios y Publicaciones, 2016, p. 71. 
jurídico, sea por olvido o imprevisión del legislador, ora porque el momento de elaborase los preceptos esa hipótesis no era imaginable". Agrega, que

se producen, propiamente por falta de ley, vacíos que deben ser solucionadas por el juez o por deba resolver el caso concreto, para lo cual se aplican las normas de integración jurídica. Asimismo, también se producen por leyes insuficientes, esto es, las que prevén consecuencias para determinados casos, pero los casos previstos por el legislador no son plenamente coincidentes con los que se presentan en la causa a resolverse ${ }^{28}$.

Aparentemente, desde la redacción de las normas procesales en arbitraje -incluido el derecho público- ante una ausencia de normas podría incorporarse figuradas y corrientes doctrinales.

\section{Arbitrabilidad y Transigibilidad}

Ahora bien, como se señaló, no es secreto las grandes lagunas normativas en los arbitrajes con el Estado ecuatoriano. Si vemos desde la óptica de la supletoriedad, la LAM y el COGEP no dilucidan lo transigible o arbitrable; y, la jurisprudencia menos. En su momento la derogada Ley de la Jurisdicción Contencioso-Administrativa pretendió establecer aclaraciones en su sexto artículo, que desarrollaba el concepto de potestad discrecional, que, en vez de aclarar la situación, ahondó confusiones retenidas hasta la actualidad. Pero lo arbitrable y transigible, merece ser aclarado desde el texto normativo y no bajo interpretaciones infundadas, que en los siguientes párrafos intentaremos dar algunas luces.

El hecho es que debemos partir nuestro análisis desde la declaración efectuada por la Constitución de 2008, cuando claramente y sin condición, dice: “Art. 173.- Los actos administrativos de cualquier autoridad del Estado podrán

28. Ibídem. 
ser impugnados, tanto en la vía administrativa como ante los correspondientes órganos de la Función Judicial" 29.

En Colombia, Susana Montes de ECHEVERría, citada por Juan PabloAguilardiferenciaquenoeslomismolaactuacióndelEstado mientras actúa bajo su función de imperio, de las actuaciones dentro de una relación contractual y en tal virtud considera que las manifestaciones de voluntad de la Administración en un contrato estatal pueden ser analizadas y juzgadas por el juez arbitral. Dentro de estas, cabría la arbitrabilidad o "revisión" de la legalidad los aspectos fundamentales que generalmente son asunto de controversias: multas, resolución de terminación unilateral y anticipada, ejecución de garantías, la liquidación del contrato e interpretaciones del contrato en aspectos técnicos y/o jurídicos ${ }^{30}$.

Es claro, que existe ciertos prejuicios sobre la arbitrabilidad de los actos administrativos e incluso una reciente sentencia de anulación sostuvo que, "[p]or principio de orden público el acto administrativo emitido el 05 de octubre de 2015 no pudo ser impugnado $u$ 'objetado' en sede arbitral, aun cuando las partes hubieran previsto convencionalmente esta posibilidad [... $]^{\prime 31}$. En este caso la Corte Provincial, de la lectura de la decisión, sin fundamento sobre esta conclusión, diferencia implícitamente las competencias en "sede arbitral" de las de "sede judicial", cuando en materia de contrato público son equiparables, salvo las excepciones expresamente previstas por la norma. Adicionalmente y más grave, es que los contratos que contienen cláusula arbitral, impiden a las partes accionar la justicia ordinaria, por lo que señalar que en "sede arbitral" no puede ser impugnado un acto administrativo, se crea una paradoja al imposibilitar la impugnación en todas

29. Constitución de la República, N. 6, Art. 173.

30. J. P. Aguilar, "Sobre las Materias Arbitrables en el Derecho Administrativo", Revista Ecuatoriana de Arbitraje, No. 1, 2009, p. 27.

31. Corte Provincial de Pichincha, Causa No. 17100-2018-00006, Sentencia, 02/08/2018. 
las vías, configurando un estado de indefensión, a todas luces inconstitucional.

Los actos administrativos, no son más que el vehículo para la declaracióndevoluntad delaAdministración ${ }^{32}$ yestosnoprovienen de la divinidad. Son producciones en el ejercicio del poder que no sólo pueden ser sometidos a control; sino que deben someterse a control, como lo dice la mentada disposición constitucional citada antes. De lo contrario no se estaría comprendiendo, que el trabajo histórico del derecho administrativo y de la sociedad, justamente fue limitar la tiranía, con lo cual declarar que los actos administrativos no son arbitrables -o peor aún, revisables- es equivalente a afirmar "El Estado soy yo" atribuido al Rey Luis XIV de Francia, que contribuyó al levantamiento y revolución en ese país, siglos atrás.

La sentencia de la Corte Provincial, confirma cierto criterio que interpreta erróneamente la ejecutoriedad y presunción de legitimidad y sobre todo la potestad discrecional de los actos administrativos, con la posibilidad de ser sometidos al control de legalidad por inobservar el ordenamiento jurídico, sea por los jueces o árbitros.

En el campo de la potestad discrecional, que es el punto medular de debate, la misma proviene de una evolución de los denominados Actos Políticos o de Gobierno que en alguna época pasada no eran revisables, pero fueron debatidos desde inicios del siglo pasado. Así, en el derecho francés el Consejo de Estado, bajo el control retenido de la legalidad de los actos administrativos, tampoco podía revisar el carácter político o de gobierno. Pero con la evolución del derecho, hoy en día nada escapa de control en ninguna legislación, incluida la ecuatoriana. Lo que sí, la potestad discrecional, pese a

32. Código Orgánico Administrativo, N. 5, Art. 98. 
esfuerzos doctrinarios y normativos ${ }^{33}$ sigue ocasionados criterios encontrados, pero el propósito de la figura es vital para distinguir el campo de acción de la autoridad pública por el antecedente del principio de legalidad, pues por más abundantes normas que se generen -que no es la idea-jamás podrán delimitar todo el margen de acción del poder público y de ahí, su utilidad.

Pero esta figura también tiene debates en el derecho administrativo en Estados Unidos ${ }^{34}$-Common law-elcual sostiene que los actos administrativos ${ }^{35}$ denominados political quiestions (actos políticos) no admite recursos contra los Tribunales Judiciales, salvo un control retenido. Empero, debe distinguirse que los actos políticos en derecho anglosajón no entran en el contractual con los gobiernos y sus agencias, que tienen una regulación distinta que proviene del precedente interno y jurisprudencial -no del principio de legalidad-. Además, los litigios o arbitrajes derivados de la relación contractual con el Estado, son considerados materia civil y resueltos por tribunales civiles, que considera al Estado y al particular como dos partes iguales, a diferencia del derecho público ecuatoriano.

Pero para distinguir los actos políticos "irrevisables" y distinguirlos de la parte revisable de los actos administrativos, tiene que ver con lo que ahora es la figura de la potestad discrecional. A manera de ejemplo citamos lo previsto en la Ley Orgánica del Sistema Nacional de Contratación Pública (en adelante, LOSNCP) en relación al ejercicio de la facultad discrecional al declarar la terminación unilateral del contrato, que dice: “ante circunstancias técnicas o económicas imprevistas o de caso fortuito o fuerza mayor, debidamente

33. Reglamento para el Control de la Discrecionalidad en los Actos de la Administración Pública, Decreto Ejecutivo No. 3179, RO No. 686, 18/10/2002.

34. J. Clarke Adams, El Derecho Administrativo Norteamericano, Editorial Universitaria de Buenos Aires, 1974. p. 72.

35. El derecho administrativo y acto administrativo del sistema anglosajón tienen una naturaleza y definición distinta. 
comprobadas, el contratista no hubiere accedido a terminar de mutuo acuerdo el contrato" 36 . Una decisión "política" habría sido justamente terminar la relación jurídica.

Evidentemente, en este caso la norma intencionalmente es ambigua y deja a discreción de la entidad pública, la posibilidad de terminar el contrato, sin que esto implique incumplimiento. Los jueces o árbitros no podrán cuestionar propiamente los argumentos que sostienen la decisión, pero sí podrán analizar si la terminación respetó los derechos del contratista y demás disposiciones, como la liquidación, el avance de ejecución, la correcta imposición de multas, etc. Esta distinción que la doctrina y la jurisprudencia, han logrado.

Ahora bien, es de destacar y aclarar, que el procedimiento contencioso administrativo según el COGEP ${ }^{37}$ aplicable al arbitraje, es válido siempre y cuando se encuentre derivado de un contrato. Pues del resto de acciones judiciales previstas en el art. 326 del mismo COGEP como la "anulación de normas", la "lesividad", el "silencio administrativo", la "coactiva", no contemplan ni pueden contemplar cláusulas arbitrales, pero la razón de fondo para que estas no puedan ser arbitrables es porque la ley no prevé la fórmula arbitral, más no porque contienen un elemento sagrado o divino.

En conclusión, si los actos administrativos no podrían ser revisables por un Tribunal Arbitral entonces, ¿qué le quedaría por resolver dentro de su competencia? Pues, la voluntad administrativa dentro del contrato, se manifiesta por intermedio de este único canal.

36. Ley Orgánica del Sistema Nacional de Contratación Pública, Art. 93, RO Sup. 395, 04/08/2008.

37. Código Orgánico General de Procesos, N. 20, Art. 326. 


\section{El aRbitraje en los distintos contratos estatales DEL ECUADOR}

A continuación, veremos una noción general de las relaciones contractuales con el Estado ecuatoriano y su posibilidad arbitral.

\subsection{Tratados Bilaterales de Inversión}

La Corte Constitucional al dictaminar sobre la denuncia de los tratados bilaterales de inversión (en adelante, TBIs), interpretó el artículo 422 de la Constitución señalando que la prohibición ahí no contemplada era aplicable a aquellos tratados o instrumentos internacionales relativos a la integración regional y como tales, puedan instituir instancias arbitrales regionales $\mathrm{u}$ órganos jurisdiccionales de designación de los países signatarios, para la solución de controversias entre Estados y ciudadanos de Latinoamérica. Sin embargo, nada dijo la Corte, respecto de la posibilidad de remitir las disputas de inversiones o cualquier otra, entre el Estado y personas naturales jurídicas o privadas a través de la legislación doméstica, abriendo así otras posibilidades ${ }^{38}$.

En todo caso, es necesario distinguir entre el arbitraje basado en tratados y como tales regidos por el derecho internacional, con las disputas derivadas de contratos. Sebastián ESPINOSA ${ }^{39}$ considera que las disputas basadas en Tratados atañen al ejercicio de prerrogativas soberanas del Estado que por medio de sus actos puedan limitar el derecho de propiedad de inversionistas. Continúa el autor explicando que, estos deben ser analizados bajo la lupa del derecho internacional y su responsabilidad internacional como Estado, lo que lo distingue ampliamente del incumplimiento

38. Corte Constitucional del Ecuador, N. 15.

39. S. X. Espinosa Velasco, Ecuador an International Investment Law and Policy, Ed. Boekenplan 2019, p. 160. 
contractual. Tampoco se descarta la concurrencia de estos dos escenarios.

\subsection{Contratación Pública}

Ahora bien, estos contratos están normados por la LOSNCP, los cuales prevén los tradicionales contratos públicos: adquisición de bienes y servicios, ejecución de obras y consultorías ${ }^{40}$. El objeto de estos es satisfacer las necesidades sociales e institucionales ordinarias, que realicen las entidades del sector público. Esta LOSNCP prevé en el 104 los procesos de mediación y arbitraje en derecho. La cláusula arbitral suele estar prevista en los modelos de "pliegos precontractuales" los mismos que son reflejados en el contrato definitivo ${ }^{41}$.

Los contratos públicos, por ejemplo, son la construcción de puentes o carreteras requeridos por el Ministerio de Transporte y Obras Públicas; adquisición de maquinaria (bienes) por parte de municipios para mantenimiento de vías; entre otros.

\subsection{Contratos de Inversión}

Estos contratos son atípicos, pues su fin es incentivar la inversión nueva, productiva, nacional y extranjera dentro del sector privado del país. La obligación del inversionista es aportar la inversión y la contraprestación del Estado, es garantizarle el derecho de propiedad, estabilidad tributaria y otros beneficios acordados en el contrato. Por lo tanto, en lugar de la existencia de un "objeto del contrato" en el sentido tradicional, se trata de un acuerdo del respeto de carácter impositivo favorable a cambio de la inversión.

40. Ley Orgánica del Sistema Nacional de Contratación Pública, N. 36, Art. 1.

41. Ídem, Art. 104. 
El Código Orgánico de la Producción Comercio e Inversiones (en adelante, COPCI) -que es la norma que regula los contratos de inversión-, mediante reciente reforma de agosto de 2018, determinó que para los contratos de inversión que superen los USD \$ 10 Millones "[...] el Estado deberá pactar arbitraje nacional o internacional en derecho" ${ }^{\prime 2}$. En este caso excepcional la legislación, se interpreta que ahora el arbitraje es la única forma de solucionar las controversias como regla general, pues del texto se colige que "deberá" pactarse el arbitraje. La propia Ley, enuncia las opciones de normas procesales para el proceso arbitral, que pueden ser estipuladas en los contratos:

(i) Reglamento de Arbitraje de la CNUDMI - Naciones Unidas administrado por la Corte Permanente de Arbitraje de la Haya (CPA); (ii) Reglamento de Arbitraje de la Corte Internacional de Arbitraje de la Cámara de Comercio Internacional con sede en París (CCI); o, (iii) Comisión Interamericana de Arbitraje Comercial (CIAC). La disposición también expresamente señala que las reglas de arbitraje de emergencia no se aplican en ningún caso $^{43}$.

Es interesante observar la evolución del sistema jurídico positivo, pues tradicionalmente uno de los aspectos que no eran arbitrables, eran justamente los tributarios. Pero ahora este escenario es un hecho, por mandato de la ley, que debe prevalecer sobre las teorías interpretativas.

\subsection{Contratos de Concesión}

La participación del sector privado en los sectores estratégicos y servicios públicos podrán encargase por gestión delegada por medio de este tipo de contratos, al sector privado. Usualmente este tipo de contratos,

42. Ley para Fomento Productivo, Atracción Inversiones Generacion Empleo, Art. 14., RO Sup. No. 309 de 21/08/2018.

43. Ibídem. 
pueden ser suscritos para la explotación del espectro radioeléctrico, para los contratos de exploración y explotación de campos del sector petrolero, concesión de carreteras para mantenimiento y recaudación de peajes. La base legal de estos contratos la tiene el $\mathrm{COA}^{44}$ en donde se prevé la alternativa de mediación y arbitraje en derecho, de conformidad con la cláusula compromisoria respectiva.

Es interesante ver que, pese a nuestra influencia europea, al menos en Ecuador el sistema ha tendido hacer más rígido del europeo. Ya que en países como Francia, los Contratos de Concesión tienen la naturaleza de contratos civiles y se ventilan en juzgados civiles. No así en Ecuador.

\subsection{Alianzas Público-Privadas}

Se trata de una Alianza (por intermedio de un contrato) entre una o varias entidades del sector público y un gestor privado. Estas alianzas están consideradas para proyectos de gran envergadura, relativos a aspectos portuarios, aeroportuarios y similares. Los que pueden adaptarse en algunas modalidades contractuales, como por ejemplo contratos tipo $\mathrm{EPC}^{45} \mathrm{y} / \mathrm{o} \mathrm{OM}^{46}$.

La ley ${ }^{47}$ que regula las Alianzas Público-Privadas, dentro estos "contratos de gestión delegada", como se los califica, permiten pactar el arbitraje nacional o internacional ${ }^{48}$. En este último caso, indica que debe ser en instancia arbitral regional latinoamericana. La norma también se preocupó de exceptuar como materia arbitrable, en este tipo de contratos, los aspectos tributarios, así como los derivados directamente de la potestad legislativa y regulatoria del Estado ecuatoriano.

44. Código Orgánico Administrativo, N. 5, Arts. 76 y 126.

45. Engineering, Procurement, Construction.

46. Operation and Maintenance.

47. Ley Orgánica de Incentivos para Asociaciones Público-Privadas, RO Sup. No. 652, 18/12/2015.

48. Ídem, Art. 18. 
Es decir, estos últimos no serían materia de arbitraje, es decir, no sería materia arbitral o transigible, pero porque la propia Ley así lo dispone. 